\title{
Building Competitive Edge
}

\author{
Nagasimha Balakrishna Kanagal ${ }^{1}$ \\ ${ }^{1}$ Indian Institute of Management, Bangalore, India \\ Correspondence: Nagasimha Balakrishna Kanagal, Faculty Block E-205, Indian Institute of Management, \\ Bannerghatta Road, Bangalore 560076, India. Tel: 91-80-2699-3185.
}

Received: May 29, 2018 Accepted: June 25, 2018 Online Published: August 21, 2018

doi:10.5539/ijms.v10n3p91 URL: https://doi.org/10.5539/ijms.v10n3p91

\begin{abstract}
The objective of a marketing strategy formulation and appropriate execution is to improve the long run financial performance of a firm / brand that includes improving market share, improving market capitalization, improving return of investment and payback period. The marketing strategist should take cognizance of the market forces that influences the payoffs to the firms. The influence of the competitive scenario on a firm / brand's payoff is significant and could even at times be substantial in an oligopolistic industry-market structure, where strategic inter-firm dependence could be high. In this scenario, firms / brands need to be systematically prepared to find customer favor in a competitive market; this indeed is the realm of building competitive edge. In this study, we outline the path of improving ability to the process of marketing strategy formulation and examine in greater detail the process of improving the ability to compete or the buildup of competitive edge. A buildup of competitive edge is expected to improve the firm's ability to competitive choice in the market place, through a process of improving the pro-activeness and reactiveness of the firm with respect to competitors to the satisfaction of (i) the consumers / target market, (ii) the market-society at large, as well as (iii) the policy makers regulating the competitive environment in the country / world. The improvement in the firm's ability to competitive choice should reflect both in market share as well as market profitability and lead to improved market capitalization and superior long run financial performance.
\end{abstract}

Keywords: ability to compete, competitive edge, long run financial performance, marketing strategy formulation

\section{Introduction}

The objective of a marketing strategy formulation and appropriate execution is to improve the long run financial performance of a firm / brand that includes improving market share, improving market capitalization, improving return of investment and payback period. Marketing managers and marketing strategists are constantly battling on the marketing war field to achieve these objectives and they invariably use the methods of (i) strategic marketing decision making and decision control of marketing strategy; (ii) marketing planning (or strategizing for marketing), and marketing planning control; (iii) marketing strategy execution and control of marketing execution; (iv) measurement of performance based on objectives and metrics and associated performance control that includes both strategic control, and tactical control; (v) dynamic adjustments to competition and market; and (vi) organization of structure to support strategy and execution as well as control of structure that normally takes shape as organizational interventions.

The marketing strategist should take cognizance of the market forces (company, customer, context and competitor) that influences the payoffs to the firms. The company refers to the vision, mission, goals and objectives of the business that drive strategy. The customer includes the target market itself which is the firm to customer relationships. The context refers to the business environment that encompasses the (i) market-society and institutional environment that includes externalities such as the government, the channel, consumer action groups, vendors, collaborators, banks and financial institutions; (ii) the public that includes apart from the market society and institutional environment, other stakeholders such as investors, customers clients, suppliers, and other members of the end to end value chain in which the considered firm is participating; (iii) the relevant macro-environment that includes standards setting organizations and the corresponding technological environment; the political situation and regulations governing the business; supplier sources; the state of the economy and the socio-demographic state of the populations under consideration; the availability and prices of natural resources that may be required for business. 
In addition to company, customer, context, and their influences, the performance and as such the payoffs to the firm of its value providing activities, is also tightly coupled to the state of the industry in which the considered firm / brand is operating and hence the firm needs to take into account the competitive scenario in which the business is operating. The influence of the competitive scenario on a firm / brand's payoff is significant and could even at times be substantial in an oligopolistic industry-market structure, where strategic inter-firm dependence could be high. In this scenario, firms / brands needs to be systematically prepared to find customer favor in a competitive market; this indeed is the realm of building competitive edge. An illustration is the competition effects in the airline industry where customers are information enabled, customers are price sensitive, the industry has been deregulated, there is common market demand, the airlines can differentiate themselves, discount airlines are operating, and there is strategic interdependence in the industry (Lee \& Kim, 2017); building competitive edge in such a scenario is of prime importance.

\section{Method / Research Questions}

In this study, we outline the path of improving ability to the process of marketing strategy formulation, and examine in greater detail improving the ability to compete or the buildup of competitive edge. We then draw implications for marketing strategists. The method used is to conceptualize the strategic marketing process by laying out the linkages of the various interacting elements in the portfolio of the marketing strategist. Definition research in competition is carried out next, with subsequent theory discussions to explain the strategic path to buildup of competitive edge, and the dynamic path to build competitive edge. The study concludes with implications for marketing strategists.

\section{Improving Ability to the Process of Marketing Strategy Formulation}

The process of marketing strategy formulation also called as the strategic marketing process is diagrammatically laid out in Figure 1. The organizing paradigm for improving ability to the process of marketing strategy formulation of a brand / firm (hereinafter called 'the firm') is through the trine principle of (i) firm becoming customer centric (ii) firm developing market orientation and (iii) firm building competitive edge.

The firm becomes customer centric by attending to customer value, customer lifetime value, customer relationships and customer relationship management, suitable customer analysis for marketing strategy insights, effective customer experience management wherever applicable. In the process the firm relies on its understanding of customer needs and wants; mapping it with the corresponding features, benefits, performance, functionality, and business model.

The firm develops market orientation by having adequate focus on the development and sustainment of competitive advantages or the strategic thrusts of the business, adapting marketing strategy through suitable marketing strategy reformulation wherever appropriate, attention to public image management, and customer satisfaction processes. Embedded in competitive advantages are both core competencies and value competencies. Competitive advantage obtainment, and sustainment enables an organization to develop market orientation that leads to effective formulation of marketing strategy. The fructification of competitive advantages through appropriate competitive marketing strategies, functionality focus, and business model gains is needed to gain in business for the firm. Such competitive marketing strategies includes competitive value proposition, competitive assurance, competitive freewheeling, competitive communication, competitive trial, competitive loyalty, avoidance of customer dissatisfaction, competitive transaction, competitive innovation, and turnaround of competitive disadvantage.

Along with development of market orientation, and beyond sustainable competitive advantages, is the ability to compete or build competitiveness / build competitive edge. This is discussed in detail in the subsequent section.

For effective marketing strategy formulation the firm should accommodate the convergence between the business purpose of value creation, and the business purpose of firm orientation; this is necessary for making market orientation effective. In addition for an effective competitive marketing strategy formulation, the firm should accommodate the convergence of value creation and firm orientation with competitive orientation.

The marketing strategy formulation cannot afford to ignore the aspects of operational excellence. This encompasses effective and efficient operations including manufacturing scale and scope advantages, relative cost advantages over competition in marketing channels, effectiveness of financial management and structuring practices, efficient and effective purchasing and sourcing strategies through good supply chain management, cluster advantages, and competitive alliances.

Suitable customer centricity, and effective market orientation in marketing strategy leads to competitive choice; building competitive edge / appropriate competitiveness reflects in competitive choice; good operations 
excellence leads to competitive gain. Improving both competitive choice and competitive gain leads to improved market capitalization, improved return on investment, improved market share and superior long run financial performance, which is the objective of marketing strategy of a firm / brand.

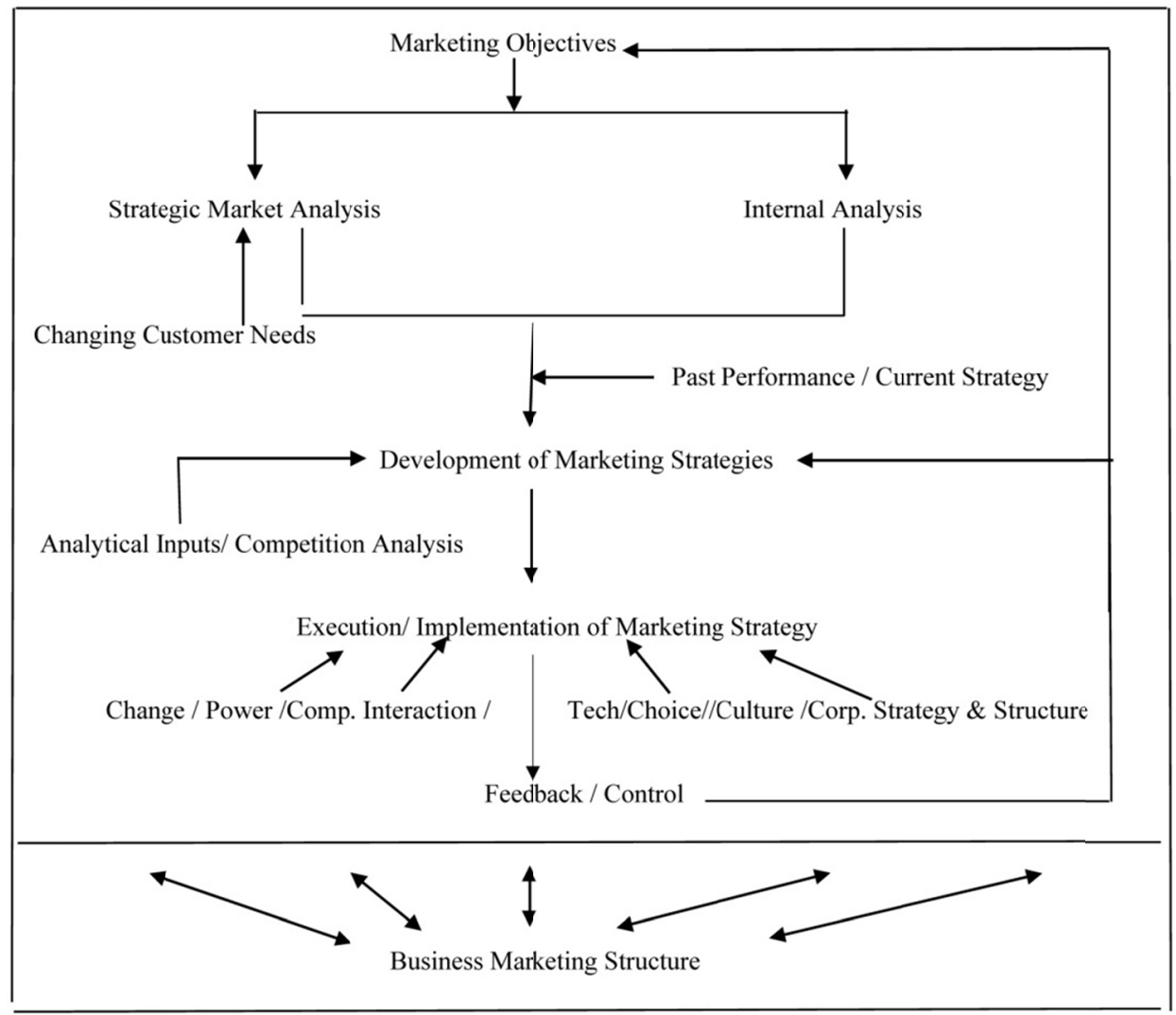

Figure 1. Strategic marketing process

\section{Understanding Competition}

\subsection{Competition as Defined}

Competition is the process of active rivalry between the sellers of a particular product as they seek to win and retain buyer demand for their market offering. With the strategic thrust being defined by the obtainment of sustainable competitive advantages (such as low cost, cost focus, differentiation, differentiation focus, synergy, value discipline (performance superiority, operational excellence, customer responsiveness - Day \& Reibstein, 2006), market mechanisms (product leadership, performance excellence), and preemption), that derive from the resource position of the firm and are part of a firm's need to be market oriented, firms / brands need to go beyond competitive advantages to secure business. Beyond competitive advantages is the ability to compete or competitiveness, and marketing strategists will find it useful and effective to target explicit attention to a systematic and formal method of addressing competition in an effort to build competitiveness. With the rise of outsourcing, offshoring, and globalization, the last two decades has seen an upsurge in competition with key multinational corporations holding the key core competencies within their home country firms and releasing the power to generate business to the emerging markets (Goralski, 2011); as such there is an increasing necessity to identify and understand competition. The following delineation in this section is towards such an attempt, in outlining the process of building competitiveness or improving the ability of a firm / brand to compete.

\subsection{Identify Competitors}

The first aspect is that identification of competitors is a matter of degree. For illustration consider a bottle of water from Appolinaris (Germany) which is a fine table water often called the 'queen of table waters', which is in competition from San Pellegrino (Italy) and Volvic (France) in the bottled water category; Appolinaris is in competition with Perrier (France) in the carbonated - non-carbonated bottled water category; Appolinaris is in competition with Sprite (Coca-Cola brand) in the calorific soft beverages category; and Appolinaris is in competition with Coca-Cola and Pepsi-Cola in the soft beverages category (Rao \& Steckel, 1998). 
The second aspect is competitors can be identified as (i) local, (ii) national, (iii) regional, and (iv) global. For illustration, in the detergents category in India, 'Ghari' detergent (Ghadi / Ghari in Hindi is clock or watch; RSPL India Ltd.) is a national competitor to Surf Excel (Hindustan Unilever); however Tide (Proctor \& Gamble), is a global competitor to Surf Excel.

The third aspect is (i) near competitor vs (ii) distant competitor. For example in the car market in India, BMW is a near competitor to Mercedes Benz, both being luxury cars; however Nano from Tatas, or Alto from Maruti Suzuki is a distant competitor to Mercedes Benz.

The fourth aspect of identification of competitors is the ability of a firm to clearly demarcate current competitors and future competitors. Current competitors can be near or distant; can be local, national, regional or global. Potential competitors are recognized by the threat they pose to the firm/ brand; what are their entry barriers in the industry; and whether they can be blocked from coming in. Potential competitors could also be identified by the markets that are served by other firms in the industry; an Indian apparel export firm exporting to Europe will find another apparel export firm in Bangladesh as a potential competitor as Bangladesh is in the same trade block as India with respect to Europe.

In the FMCG / CPG categories (Frequently Moving Consumer Goods / Consumer Packaged Goods), competition is intense due to low switching costs and relatively high market penetration. Being a frequently moving purchase goods category, brand switching matrices aid in identifying competitors (brands between whom there is significant switching are more closely tied in competition than brands between whom, switching is low).

Substitution in use analysis is a useful way of identifying competitors based on the choices made by customers (their consideration sets) and the brands they would buy if their chosen brand is unavailable. Perceptual mapping, product use associations, and forced choice / product deletion could be other ways to identify competitors. Within categories, analysis of inter-purchase times could also give leads to identify competitors (Rao \& Steckel, 1998).

\subsection{Understand Competitors}

One of the important aspect of evaluation of competitors lies in assessments on their (i) objectives; (ii) commitments; (iii) size, growth, and profitability; (iv) strengths and weaknesses; (v) image and positioning; (vi) exit barriers; (vii) cost structures (viii) organization and culture; and (ix) current and past strategies (Aaker \& McLoughlin, 2014). It is also to be examined if the competitors can be grouped based on their assets and competencies as well as their investment patterns to understand their intent. The level of commitment displayed by competitors is also an indication of the intensity of competition in the market. Commitment also makes way to make strategic moves of the firm credible to the competition (Dixit \& Nalebuff, 2010). It is also useful to understand the dimensions of competition on which competitors' can leverage themselves in the market, and what needs to be done to cope up with such a situation. Assessment of exit barriers could also indicate if firms intend to conduct any guerilla warfare exercises. Markets with both low entry barriers and low exit barriers are called contestable markets; as in the case of airlines market wherein the rivalry is intense and can lead to wars of attrition based on price. It is also useful to understand the differentiation to be achieved by each competitor, and whether these differentiation factors are relevant and useful to customers (Aaker \& McLoughlin, 2014).

Competitor profiles are usually expressed in terms of a competitor strength grid. The relevant dimensions of competition that includes their strengths, their skills, their resources (assets and capabilities), and their investments are placed on one axis of the grid in a relative order of importance. Firms identified as competitors are then each plotted on the second axis depending on how well, or how fairly, or how poorly they match up on each of these competitive dimensions.

Information obtainment about competitors is an important aspect in understanding competitors. Positive information asymmetry about the customer and the market with respect to competition can result in information advantages that can lead to competitive edge.

Extant research (Balachander, Gal-Or, Gaylani, \& Jiyoung Kim, 2017) provides one useful method to understand competitors on the basis of an analytical framework of competition; their research shows that firm's product strategies reflect their quality positioning, a high quality firm will always add a feature in their standard variants or models unless the cost of that feature is high in which case it is offered as an optional, a low quality firm will always provide features as an optional add-on unless the cost of that feature is low, the product strategies happen this way so as to avoid price competition in the markets and enhance market segmentation. 


\section{Discussions on Strategic Path to Build Competitive Edge}

Once competitors have been identified and marketing strategists develop some knowledge of competitors as outlined above, the first aspect of the strategic path to build competitive edge, is to necessarily and appropriately conjecture about competitors and their moves, on competitive dimensions about which firm is seeking to win in favor with the customer / target market. As such it is necessary to first identify the dimensions of competition about which a firm needs to win in favor with the customer and hence needs to develop appropriate conjecturing. The dimensions would be both strategic (dimensions gaining in importance due to long term implications, huge investments or need to manage uncertainty / risk), and tactical (dimensions impacting functioning of the firm / brand in the market up to and including annual marketing plans). Inappropriate conjecturing would result in loss of money in business as well as delay in proaction and reaction that leads to competitors gaining with the customers. To develop appropriate conjecturing and prevent inappropriate conjecturing, principles of rational expectations can be used.

The principle of rational expectation is twofold: (i) each firm should be and is smart enough to have rational expectations or appropriate conjecturing of competitor behavior; (ii) each firm should be and is smart enough to have rational expectations with regards to the beliefs that the competitor holds about its own behavior or to say that the other firm is equally smart. Succinctly rational expectations hypotheses summarizes into the twin principle of (i) I know you; and (ii) I know you know me.

Competitive conjecturing through rational expectations leads to an understanding of competitive dimensions open on rational expectations or the dimensions about which conjecturing is obvious in the market place; and also leads to an understanding of competitive dimensions, not so obvious to rational expectations and hence closed on rational expectations.

Dimensions of competition that are open to rational expectations are competitive rivalry dimensions; in a retail setting, dimensions such as store expansion, store format (discount store, mass merchandiser, super market, hyper market) about which player firms in the industry could carry on health rivalry to obtain good relative performance and necessary impact in the market place. Competitive conjecturing leading to competitive dimensions not so obvious to rational expectations are the strength building dimensions. Advertising can be at times a strength building dimension which when successful leads to building brand equity; advertising that is part of inter-firm rivalry is referred to as comparative advertising. Advertising thus has an impact on sales, and is measured by sales-advertising models; further the impact of advertising on sales is higher with increased product market competition (Y.K. Kookmin \& J.J. Kookmin, 2013).

The second aspect of the strategic path to build competitive edge is to understand the possible competitive equilibrium that would exist in the industry. Normally all competitive relationships can be categorized to fall into one of the three equilibriums: (i) Nash equilibrium where no player has the incentive to deviate from it's strategy given that the other players do not deviate (Rasmusen, 1998); each player independently strategizes maximizing it's profits; (ii) Stackelberg equilibrium or leader-follower equilibrium where in the leader moves first and the follower reacts to the leader's choice; the leader plays that strategy (knowing the reaction curve of the follower) maximizing it's payoff (Rasmusen, 1998); each player maximizing it's profits; (iii) Collusive equilibrium wherein players get together to maximize their joint profits; collusion is regarded as anti-competitive. Strategic moves by competing firms moving towards competing equilibrium, are called as strategic interdependent moves, as the actions of one player affects the payoffs of the other firms in the market; this is so in oligopolistic industries. Strategic moves can be further classified as sequential moves, or simultaneous moves (Dixit \& Nalebuff, 2010); sequential moves possibly happen in a leader-follower equilibrium, whereas simultaneous moves happen in a Nash equilibrium situation.

The third aspect of the strategic path to build competitive edge is to evolve firm's intent and game plans; capture competitor's intent and game plans. Intents evolve investment patterns to the mutual benefit of the firm and the customer; however laying out intents and capturing intents of competitor are useful in guiding and executing strategy with respect to competition. An intent is a point of view or / and a purpose about a firm's future position in an effort to capture ongoing opportunities. It is evident, that the intender has to also suggest a path to achieve the desired result of the intent. Explicit attention by marketing strategists about intent leads to a favorable strategic position with respect to competitors.

The fourth aspect of the strategic path to build competitive edge is to work around competition externalities such as government regulation as laid out by the competition policy. It is necessary for the marketing strategist to keep in mind that regulations gives regard to the welfare of the consumer / public and the process of competition is to make available to the consumer more choices, products and services efficiently produced that are price 
competitive. Competition policies encompass the judgments and decisions on anticompetitive practices such as price fixing, market sharing, agreement to restrict output, bid rigging, refusal to buy or supply, tie-in arrangement, exclusive dealing, resale price maintenance and territorial restrictions. In making judgments and decisions on anti-competitive practices, the regulations discriminate those anti-competitive practices that are 'per se' bad versus those anti-competitive practices that are guided by 'rule of reason'. Competition policies also address abuse of dominant market position and issues relating to mergers, amalgamations, acquisitions, and take overs. Abuse of dominance includes clamps on predatory pricing also called as dumping in the international context; countries choose to impose anti-dumping duty to offset the subsidies given by exporting countries to its firms to export at lower prices. Abuse of dominance also regulates price discrimination, abuse of intellectual property rights, charging excessive prices, tie-in sales and refusal to deal. As far as mergers and acquisitions are concerned, the concern is of horizontal mergers and acquisitions that could lead to market dominant position.

The fifth aspect of the strategic path to build competitive edge is the use of warfare gaming strategies. Study of Warfare is not just a study of how to win; equally important is how not to lose. From the works of Carl von Clausewitz, military general and theorist, three broad principles can be enunciated as the warfare principles, applicable to marketing (Ries \& Trout, 1986): (i) first principle is principle of force; big fish eat small fish; so too in marketing - big companies beat small companies; (ii) second principle is superiority of defense, a leader gains by blocking competitor moves; (iii) third principle is, can anything be done once game is lost - move out or divest. Marketing strategists are likely to gain by typifying competitors into categories that include planner, executor, technologists, quality conscious; one has to be wary of adverse selection in typifying competitors due to lack of information; importantly it is also not necessary to only have better people and better products on the side of the firm, it is necessary for firms to fulfill customer needs and wants.

War gaming includes the strategic square of marketing strategy which suggests the four most common types of stances taken by firms are leader, challenger, follower and nicher. Leaders are identified by the market share they hold and often play defensive warfare or the strategies to stay on top; these include blocking competitors' moves, building entry barriers, holding ground, and keeping moves in reserve against competitors, having the courage to beat oneself, or cannibalizing oneself than products of other firms cannibalizing the leader. An illustration would be a firm such as Colgate Palmolive in India who are leaders in oral care. Leaders war gaming moves include fortress or position defense strategy; proactive confrontation such as a preemptive defense move; a reactive confrontation such as a counter offensive move; defending flank positions in the market for their flagship brands; mobile defense moves or the ability to continually upgrade as Intel did with microprocessors; and strategic withdrawal from businesses when their core competencies do not match with the requirements of the market. Leaders can also communicate using signaling (such as announcements or price signals) to prevent competitors from entering its markets. Leaders also expand by: serving customers who go global; finding new uses for their product; targeting new users for their product; and encouraging increased usage.

Challengers play offensive warfare that is needed to get on top / beat leaders. Challenger attacks need to be backed by more resources than defensive moves of leaders; the subtle aspect is of being able to find a weakness in the leader's strength and carry out an attack on as narrow a front as possible to minimize resource expenditures. The introduction of Burger King as competitor to McDonalds is a good example of a challenger strategy (Ries \& Trout, 1986). Challengers war gaming includes frontal attacks on leaders, flanking attacks, leapfrog strategy, and encirclement attack. An encirclement attack is an attack of the challenger to weaken the competitor by attacking any front or all fronts. An encirclement strategy is a strategy to weaken the competitor that includes a single encirclement attack or a series of encirclement attacks with a frame of reference of the attack as narrow as that of a guerrilla to as broad as an all side frontal attack. The frame of encirclement is decided more by the frame of purpose rather than the frame of process.

Followers play flanking warfare wherein a flank is an uncontested area in the market and the firm hinges on its ability to create and maintain a separate category; tactical surprise is an important element in flanking warfare and pursuit is as much critical as attack. In India, in the passenger car market, Tatas flanked at the lower price point with the Nano (that failed because of developing a poor image). Followers can take one or more of the stances that include (i) Counterfeiter who duplicates product and sells in the market through dis-reputable dealers such as sales of Apple Computer, Rolex watches at astonishingly low prices without any assurance; (ii) Cloner who emulates leader's product as happened in the late $20^{\text {th }}$ century in the Personal Computer market, with the emergence of a number of cloners making personal computers at low prices with the open sourcing of IBM bus standards and use of the Intel microprocessor and the Intel Inside campaign; (iii) Copier or Imitator who copies but maintains differentiation in packaging, advertising, pricing, location; (iv) Adapter who adapts or improves leader's products; for example in the late $20^{\text {th }}$ century, Sony of Japan innovated and then firms such as LG, 
Samsung of Korea brought out improved versions at lower prices.

Nichers' often can play guerrilla warfare; a guerrilla firm doesn't change mathematics of a marketing war, rather a guerilla reduces the size of the battleground in order to achieve a superiority of force. Guerillas are prepared to exit quickly and would have made their money before they are over powered by the big firms. The illustration for a nicher who played guerilla warfare was the internet browser firm Netscape against Microsoft in the last decade of the twentieth century (Ries \& Trout, 1986).

It can be learnt from the works on war strategies (Greene, 2007, Vasconcellos E Sa, 2005) that marketing strategists need to keep in view the following considerations: (i) identify competitors; (ii) knowledge of the considered firm's characteristics and plans as well as the competitor's (enemy) characteristics and plans; that is to say understand the firm and its competitors with respect to their objectives, strategies, motivations, behavior as well as their strengths and weaknesses; (iii) learn to respond to obvious or evident current effects in the marketplace; it is to be noted that long run advantages are obtained sometimes as the persistence effects of current deviations or gains made by firms; (iv) have courage to beat oneself ; (v) find ways of motivating the marketing strategy team; (vi) be in alignment with the ground realities of the industry and the market; (vii) have a mindset to pro-act and react to competition with speed and flexibility; (viii) avoid groupthink; (ix) bring in focus to the marketing war gaming actions or moves by identifying the decision variables that need to be changed for optimal impact in the marketplace (the two most common being quantity produced and price), and deciding on which competitor or markets to respond (where to compete - strategy), when to respond (timing), how to respond and how much to respond (tactics); the issue of identification of the war game is sensitive and important; (x) identify and set apart resources for the war game including the ability to deter competition through suitable entry-deterrence strategies and / or buildup of barriers to entry; (xi) think long term so as to understand the big picture of the industry and marketplace; lose short term if needed to gain long term; (xii) allow competitors to make moves so as to read their tactical and strategic intent; (xiii) swing or turn in the locus of control in the industry towards the considered firm; (xiv) ignore competitor moves at times if necessary; (xv) use of tactical surprise or suddenness whenever required, catch competitors off-guard or on the wrong foot if possible; (xvi) weaken competitors wherever possible to the extent it hurts the competitors, encircle them if need be; (xvii) address competition issue from multiple angles and multiple levels; for example one firm could make global changes to a competitor move or it could make do with a local change; (xviii) attack the flanks whenever profitable; (xix) attempt to move into strategic market positions in the marketplace to gain positional advantage; (xx) fight markets, just not competition, that is to say work towards a convergence of value creation and firm orientation with competitive orientation; (xxi) adopt suitable causes if needed to fight competition - could even be a self-actualizing cause; gain moral victories if possible; (xxii) adopt appropriate communication and signaling with competition; (xxiv) learn when and how to exit markets. The ultimate aim of a warfare strategy is to win in the marketplace with minimal expense of resources through a process of consistently improving the strategic market position of a business (Gagliardi, 2005).

In terms of a competitive stance, a firm can occupy one of three positions: (i) "head-on," wherein the firm attacks the competitor frontal; (ii) "me-too," wherein the firm is a follower and takes the same position as the leader and is content with whatever market it obtains; (iii) "differentiated position," wherein the firm establishes its identity, its distinctiveness and its difference from the competitor. In the case of a differentiated position the firm can try and obtain synergy among the various segments it addresses, through consistency in R\&D, marketing, advertising, distribution, branding.

The sixth aspect of the strategic path to build competitive edge is the use of competitive intelligence. Competitors can be evaluated and assessed if information of competitors is available and the role of competitive intelligence in this regard is clear. The objectives of competitive intelligence includes: (i) how to profile competitor executives and discover their decision making process; (ii) how to protect a firm against competitor's intelligence operations; (iii) draw a line between legal and illegal or unethical activities; and (iv) move information and intelligence around the firm. Competitive Intelligence is a process, that helps in anticipating changes in the marketplace; learn from successes and failures of others; learn about new technologies, products and processes that affect a firm; learn about political, legislative or regulatory changes affecting business; and look at the firm's own business practices with open mind. The basic unit of competitive intelligence is the Intelligence Cycle that consists of four steps: (i) planning and direction; this step includes assessment of critical success factors for a firm, assess firm's competitive intelligence needs, decide on course of action to fulfill needs, and keep User informed (e.g. marketing strategist; (ii) collection of data that is effected both on primary study basis and secondary study basis and includes both the public and non-public domain; (iii) analysis that includes understanding how competitors operate on dimensions such as products, technology, financials, organizational 
strengths, alliances, manufacturing, marketing / advertising, reputation / image; analysis includes personality profiling of key competitor executives and depends on both hard data and soft information; (iv) dissemination that enables easy entry, easy retrieval; accurate data; rumors, guesses to be noted such; secure from unauthorized users; system should hold all media such as pictures, graphs, brochures, tapes; system must be able to grow as a company's competitive intelligence services grow (Kahaner, 1996).

\section{Discussions on Dynamic Path to Build Competitive Edge}

One of the basic underlying principles to the dynamic path to build competitive edge is competitive resilience or the ability to adapt (Gagliardi, 2005) to changing competitive situations; this aspect makes the difference between firms that are successful from firms that are not so successful. Building edge in competitive dynamics is further addressed by firms through suitable strategic moves and tactical moves using tools to compete, rules to compete, resources to compete, and measures to compete.

\subsection{Tools to Compete}

Management techniques include (Greenwald \& Kahn, 2005) (i) management effectiveness in exploiting technologies / market opportunities, operational effectiveness in terms of efficiency, and managing competitive advantage; competitive dynamics erode competitive advantages and firms need to periodically renew their investments in superior assets and superior capabilities to further the process of competitive advantages; (ii) competitive rivalry on competitive dimensions open or obvious to rational expectations through suitable advertising campaigns, price reductions and increases, announcement signalling, competitive brand introductions; (iii) playing dominant strategies whenever such options exist (Miller, 2003); (iv) game structuring of competitive interaction on price (price competition); price competition includes the prisoner's dilemma or non-cooperative equilibrium; structural adjustments to escape the prisoner's dilemma (such as avoiding direct competition, customer loyalty programs, self-imposed conduct of capacity limitation, most favoured nation - MFN provision, social restraints among competitors, restraint on rewarding sales over profit to sales force); tactical adjustments in other players not allowing the deviating firm to profit; (v) game structuring of competitive interaction on quantity / capacity (entry into or expanding a market); such game structures are called the entry / pre-emption games; (vi) cooperation and competition as in co-opetition (Nalebuff \& Brandenburger, 1997); (vii) hyper-competition (D'Aveni, 1994); (viii) action signalling; (ix) leapfrogging; (x) brand extensions; (xi) new ventures, alliances, mergers and acquisitions (includes both financial investment decisions to increase market share as well as strategic acquisition wherein the buyer creates a synergy in the acquired firm post acquisition).

Dynamic management techniques such as (i) competitive offsetting through tools such as consumer promotions and trade promotions; (ii) competitor action-reaction and their sequence / timing, warfare moves or war game simulations; (iii) freewheeling; (iv) resourcefulness; (v) going rate pricing; (vi) dynamic capability development, as well as the process of preventing competitors imitate a firm's resources and capabilities (Walker, 2008) ; (vii) price-wars, games of attrition; and (viii) business acumen for dynamic capture of opportunities.

Models of competition can also be used as tools to compete. Category management is an important dynamic management aspect for consumer products. Recent extant literature (Voleti, Gangwar, \& Kopalle, 2017) models the dynamics of competition for effective category management in consumer markets with a perspective to optimize profits, by integrating the demand dependencies across products and across time. Their competition construct allows for SKU-specific (Stock Keeping Unit) heterogeneity in inter-product and inter-period competition in a linear demand model framework.

\subsection{Rules to Compete}

Rules to Compete includes knowledge of competitors, competitor objectives, strategy and range of action of competitors, strengths and weaknesses; appropriate use of added value / payoffs where each firm cannot expect to make a payoff more than its added value, appropriate use of the value-net (mapping of the game of business that includes firm, competitors, customers, suppliers and complementors with corresponding interdependencies); regulations of the government for the particular product market; industry practices, tactics and associated perceptions / misperceptions arising from information gaps; rules of the game / business that arise from custom, contract or law; examination of the game from multiple perspectives that include the firm and other players to understand the rationality of each player; change in game (competitors, rules, added value, tactics / perceptions, and scope), and change in competitive stance between head-on, me-too and differentiated) (Nalebuff \& Brandenburger, 1997). However firms need to be attentive when they disrupt existing business models so as to avoid ethical disasters and focus on which rules are worth breaking. With the entry of Airbnb, hotels will never be the same, with the establishment of Amazon, retail will never be the same and with popularity of Uber, consumers have benefited with easy and effective taxi-rides; however, Uber came in to controversies in 2017, 
with its surging pricing practice and a culture of gender discrimination (Freeman \& Parmar, 2017).

\subsection{Resources to Compete}

Resources to compete include deep pockets, assets and capabilities, skills, knowledge and behaviors in technical and management systems. Resources to compete also include the continuing organization that includes a hierarchy / structure and the unification of minds, wherein unification of minds involves that the individual goals sub-serve group goals and that the group goals sub-serve the organization goals which is normally championed by a leader. Attractive location is also a resource to compete (Porter, 2008) given the existence of nearness to supply or nearness to market. Other resources include availability of incentives to produce and market by governments, availability of an intelligent work force, favorable macro-environment when businesses and markets stretch globally, and cluster advantages that could lead to availability of value adding services at the manufacturing point. Policies, processes, systems, and programs effectively developed and executed as a part of the intelligence of the organization also aid and add to the resources of the organization.

\subsection{Measures to Compete}

Guiding competitive interactions and the process of building competitive edge are the vision, mission, goals, objectives and values of the organization. Measures to compete at the micro-economic level, or the level of the brand / product / firm include metrics of competition such as brand value, market share, and relative customer satisfaction. The measure of market profitability is directly impacted by the forces of competitive rivalry, and subsumes the forces of operational effectiveness and operational efficiency; to this extent market profitability is a higher level construct indicating the health of a firm amidst competition, and gets reflected in the stock price and thus the market capitalization. Measurement of the effectiveness to the buildup of competitive edge are key performance indicators as outlined by the organization depending on the firm's characteristics, the type of product market, and the market forces that include the market context. Also needed is an understanding of win-win opportunities (positive sum game), and understanding of win-lose opportunities (zero-sum game).

The World Economic Forum (WEF) reports a GCI (Global Competitiveness Index) - a macro-economic indicator as a measure of national competitiveness worldwide, and assesses the competitiveness scenario of 140 economies. Competitiveness, states WEF, can be understood as higher productivity and is a key driver of growth and resilience. A key component of competitiveness is the capacity of a national economy to leverage talent and enhancing the ability to compete is a process with difficult trade-offs, and careful consideration for sequencing reforms (http://reports.weforum.org/global-competitiveness-report-2015-2016).

\section{Implications for Marketing Strategists}

A buildup of competitive edge is expected to improve the firm's ability to competitive choice in the market place, through a process of improving the pro-activeness and reactiveness of the firm with respect to competitors to the satisfaction of (i) the consumers / target market, (ii) the market-society at large, as well as (iii) the policy makers regulating the competitive environment in the country / world. A plan for sustainable competitive advantages with appropriate configuration / reconfiguration of competitive advantages is however necessary to drive the strategy of the business over time. Firms also need to periodically examine and rationalize if necessary their strategic business units / product portfolios to identify (i) potential areas of investment through business acumen, (ii) diversification for risk reduction, to balance the competitive edge of the entire firm. The utility of competitive edge ultimately needs to get locked into the brands of the business, making brand building an important complementary process. The improvement in the firm's ability to competitive choice should reflect both in market share as well as market profitability and lead to improved market capitalization and superior long run financial performance.

\section{References}

Aaker, D., \& McLoughlin, D. (2014). Strategic Market Management: Global Perspectives. Wiley.

Balachander, S., Gal-Or, E., Gaylani, T., \& Jiyoung Kim, A. (2017). Provision of optional versus standard product features in competition. Journal of Marketing, 81(May). https://doi.org/10.1509/jm.15.0208

D’Aveni, R. A. (1994). Hyper-competition: Managing the Dynamics of Strategic Maneuvering. The Free Press.

Day, G. S., \& Reibstein, D. J. (2006). Wharton on Dynamic Competitive Strategy. India: Wiley.

Dixit, A. K., \& Nalebuff, B. J. (2010). Thinking Strategically: The Competitive Edge in Business, Politics, and Everyday Life. New Delhi, India: Viva Books.

Freeman, E. R., \& Parmar, B. (2018). Which rules are worth breaking? MIT Sloan Management Review, Spring. 
Gagliardi, G. (2005). Warrior Marketing: Strategy for Conquering Markets. Sun Tzu's The Art of War book series. Clearbridge Publishing.

Goralski, M. A. (2011). Competition: The tipping point of power. Competition Forum, 9(1).

Greene, R. (2007). The 33 Strategies of War. Profile Books.

Greenwald, B., \& Kahn, J. (2005). Competition Demystified. Portfolio.

Kahaner, L. (1996). Competitive Intelligence. Simon \& Schuster.

Kookmin, Y. K., \& Kookmin, J. J. (2013). The moderating effect of product market competition in the relationship between advertising expenditures and sales. The Journal of Applied Business Research, 29(4), July / August. https://doi.org/10.19030/jabr.v29i4.8078

Lee, J., \& Kim, B. (2017). Airline booking limit competition game under differentiated fare structure. The Journal of Applied Business Research, 33(3). https://doi.org/10.19030/jabr.v33i3.9950

Miller, J. (2003). Game Theory at Work. McGraw-Hill.

Nalebuff, B. J., \& Brandenburger, A. M. (1997). Co-opetition. Harper Collins Business.

Porter, M. E. (2008). On Competition. Harvard Business Review Book.

Rao, V. R., \& Steckel, J. H. (1998). Analysis for Strategic Marketing. Addison-Wesley.

Rasmusen, E. (1998). Games and Information: An Introduction to Game Theory (2nd ed.). Blackwell.

Ries, A., \& Trout, J. (1986). Marketing Warfare. Plume.

Vasconcellos E Sa, J. A. (2005). Strategy Moves. Financial Times Prentice Hall.

Voleti, S., Gangwar, M., \& Kopalle, P. K. (2017). Why the dynamics of competition matter for category profitability. Journal of Marketing, 81(January). https://doi.org/10.1509/jm.15.0304

Walker, G. (2008). Modern Competitive Strategy. India: Tata McGraw-Hill.

World Economic Forum. The Global Competitiveness Report 2015-16. Retrieved from http://reports.weforum.org/global-competitiveness-report-2015-2016

\section{Copyrights}

Copyright for this article is retained by the author, with first publication rights granted to the journal.

This is an open-access article distributed under the terms and conditions of the Creative Commons Attribution license (http://creativecommons.org/licenses/by/4.0/). 